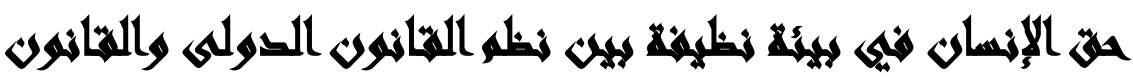

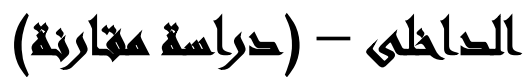

\section{[11]}

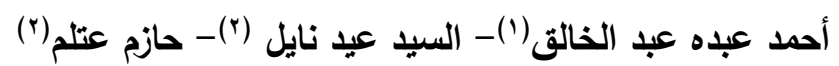

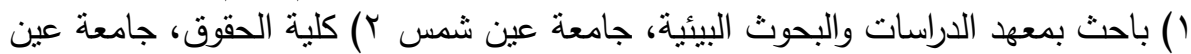

شمس

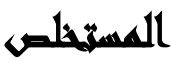

يعتبر الحق في البيئة النظيفة من أهم الحقوق في مجال الحقوق والحريات العامة، وهو

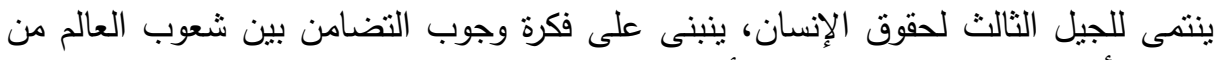

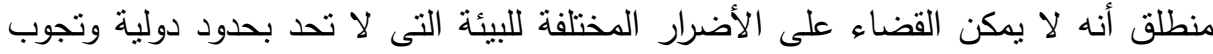

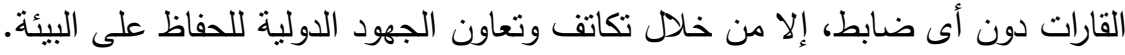

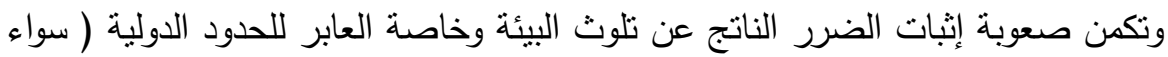

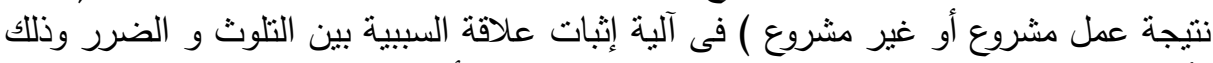

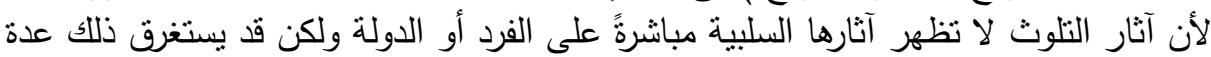

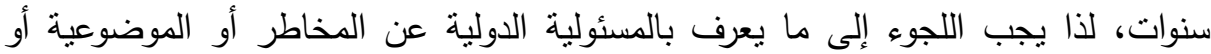

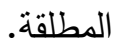

وحيث إن الدولة فى القانون الدولى هى السلطة التتفيذية فعليها أن تبذل الجهد اللازم

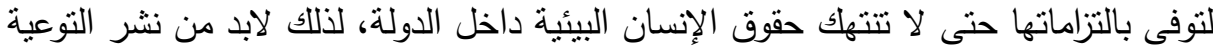

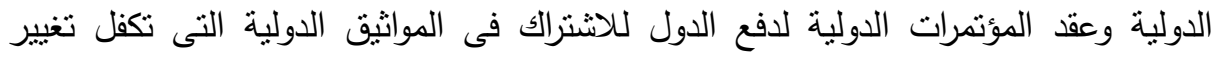

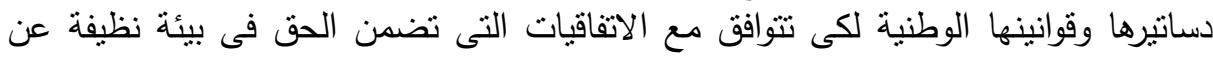
طريق الحق فى الصحة. وقد أستخدم الباحثون المنهج الوصفى فى وصى وصف وتفسير الظاهرة من خلال تحديد

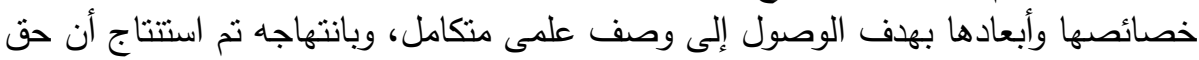

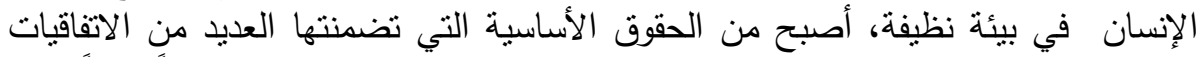

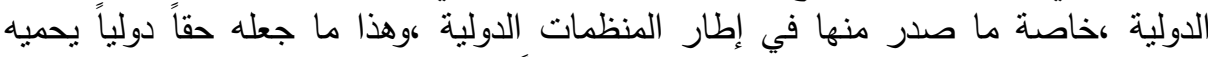

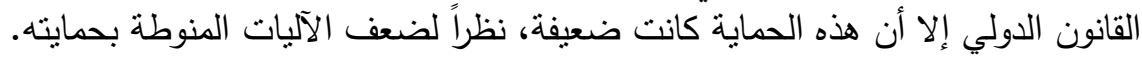

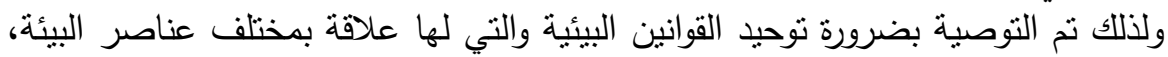

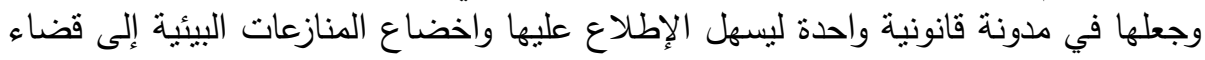

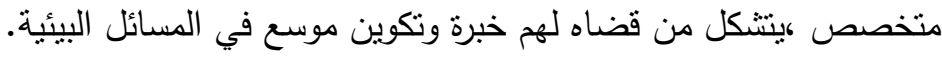




\section{المهضsar}

في عالم اليوم يفرض التقدم العلمى الكاسح نفسه فى كافة شئون الحياة وقد نم الاهتمام الدولى مؤخرا بقضية حق الإنسان في بيئة نظيفة فالبيئة مجال الحياة للإنسان وكافة الكائنات

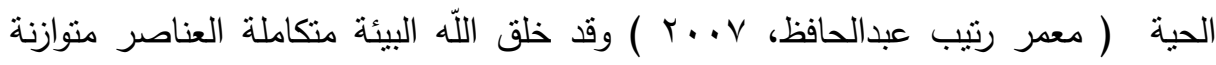

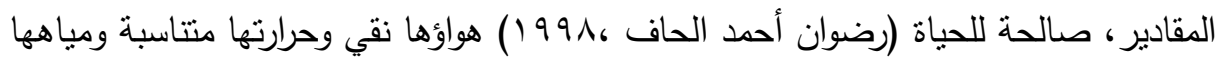
متجددة، ولكن حصل الخلل في تكامل هذه العناصر وتوازن هذه المقادير، وتلوث الماء والهواء والتربة، وارتفعت درجة حرارة الأرض، وتعرضت الحياة فيها للخطر بسبب التلوث

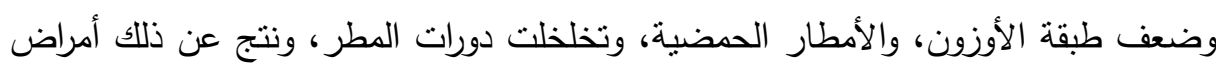
مختلفة، وتداعيات صحية متعددة (زغلول راغب النجار ، 9 ــ (هـ).

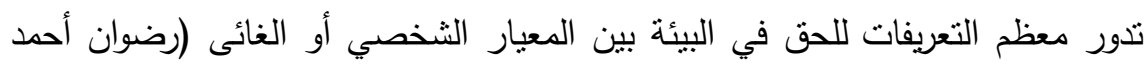

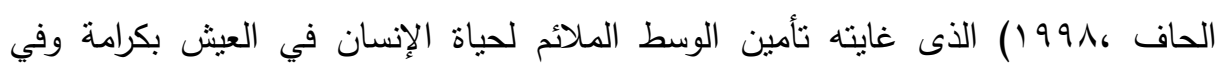
ظروف تسمح بتتمية متتاسقة لثخصيته، وبين المعيار الموضوعي الذى يضع فى اعنى النباره

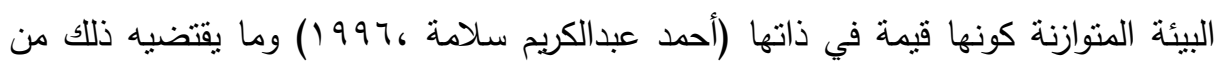
صيانة مواردها وتحسين نظمها ودفع التلوث عنها والتدهور والاستنزاف الجائر لمواردها،

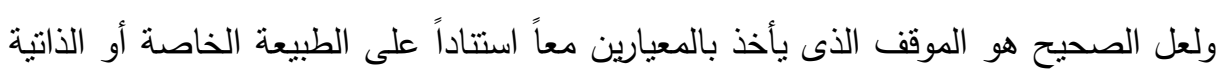

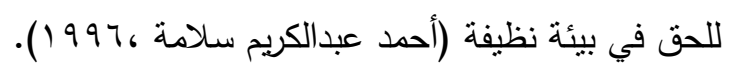
ولكن للحق في البيئة خصائص ينبغى النظر إليها، أولها الخاصية الزمنية فالزمن له له

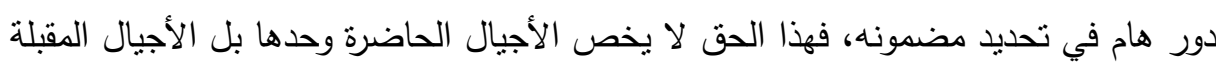

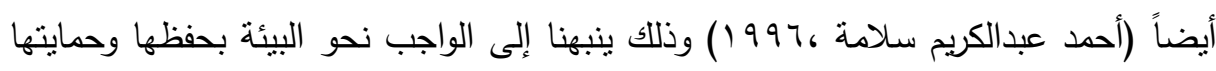

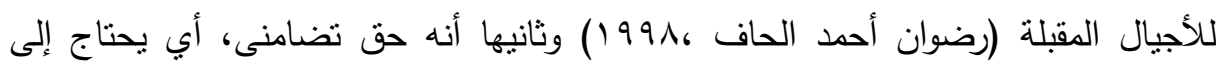

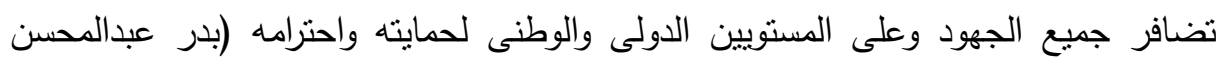
عزوز ،9 . . ج) فلا تسنطيع دولة بمفردها كفالة احترام حق الإنسان في البيئة، وذللك انطلاقاً

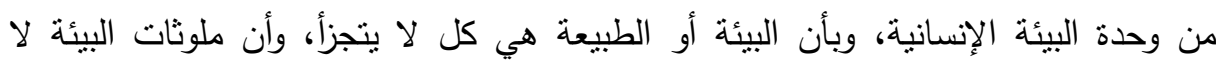

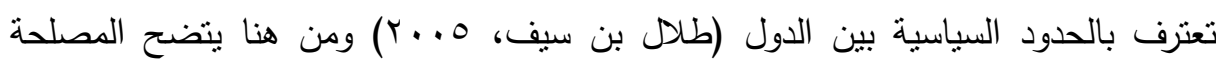

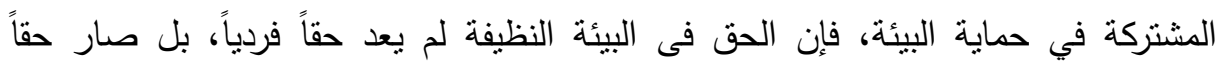


جماعياً، كحق الثعوب في تقرير المصير وحقها فى السلام (أحمد عبدالكريم سلامة،

وقد أقر المجتمع الدولي حق الإنسان في البيئة النظيفة عندما استفحل الخطر على البيئة بسب التلوث والإفساد الذى لحق بكافة عناصرها، وعندما شحت مواردها واستتزفت خيراتها وارتفعت درجة حرارتها وتعرضت طبقة الأوزون للهشاشة لذلك قرر المجتمع الدولى شعوراً منه لهاده

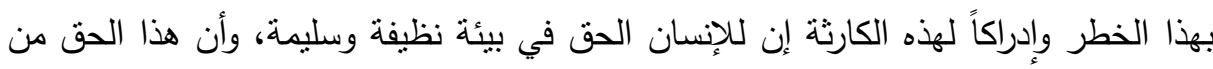

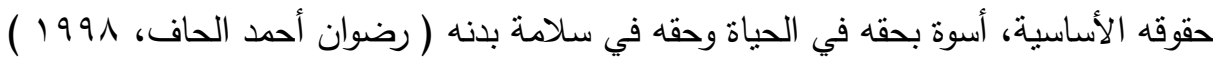
وحقه فى الحرية واتخاذ القرار والتعليم والتقاضى والتتقل وغير ذلك من حقوقه الأساسية وفقاً

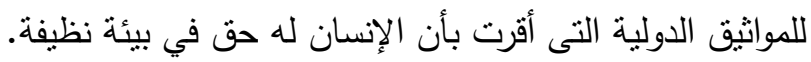
إن قرارات الأمم المتحدة والاتفاقيات الدولية المتعلقة بالبيئة تواترت على على العئه اعتبار أن البيئة

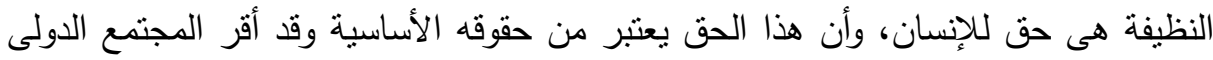
ذللك في العديد من المواقف كالتالى: ( ) العهد الدولي الخاص بالحقوق الاقتصادية والاجتماعية والثقافية الصادر عن الأمم الكتحدة

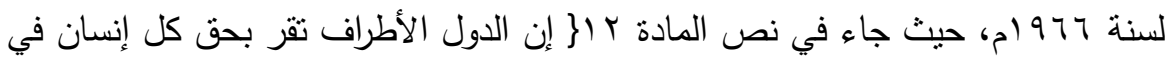

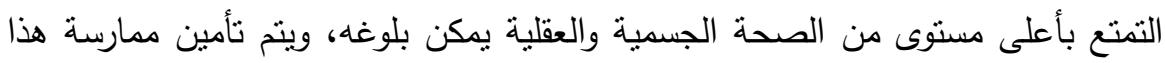

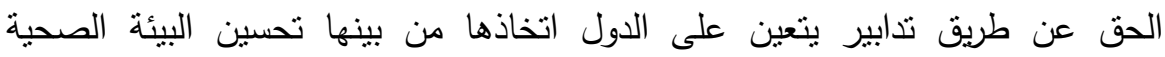
والصناعية؛ ومعلوم أن التمتع بأعلى مستوى من الصحة الجسمية والعقلية لا يتم في البيئة

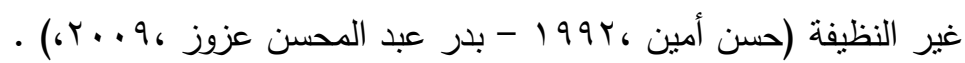

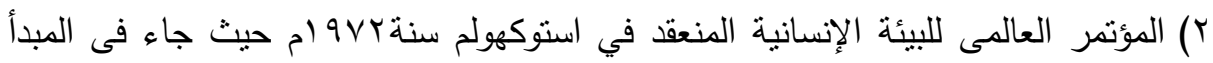
الأول من المبادئ الصادرة عنه إن \} للإنسان حق أساسي في الحرية والمساواة وفى الإنى ظروف عيش مناسبة تسمح بحياة كريمة وبرفاهية وهو يتحمل كامل المسؤولية في حماية

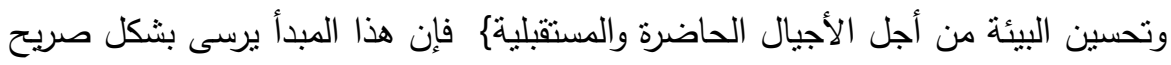

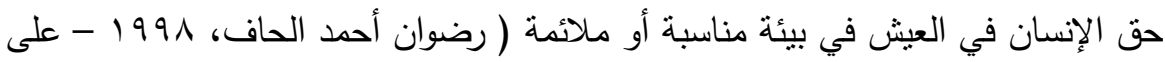

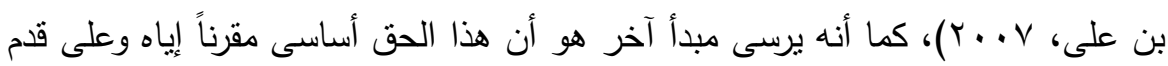

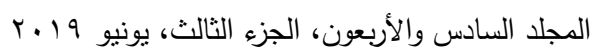


السساواة بحقوق أخرى أساسية للإنسان مثل حق فى الحرية وحق السساواة ( رضوان أحمد

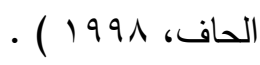

r) ميثاق حقوق الإنسان والثعوب الصادر عن منظمة الوحدة الإقريقية سنة (919 (م، حيث

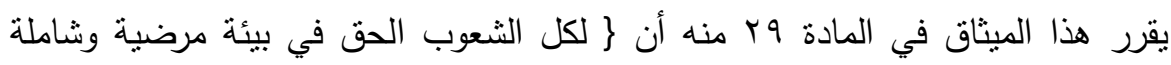

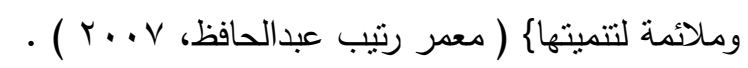

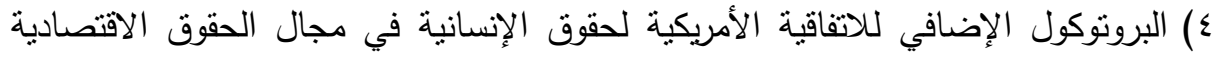

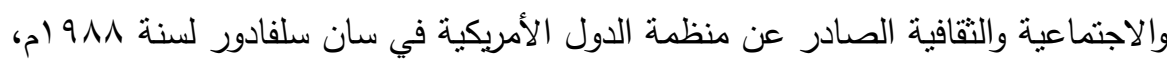

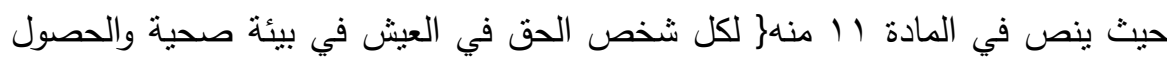

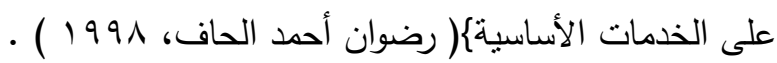

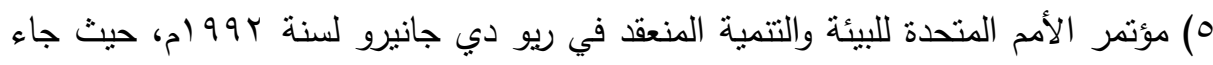

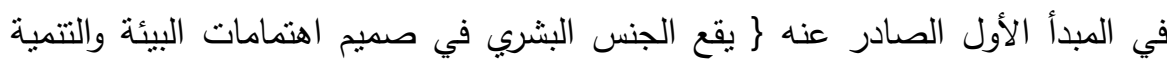

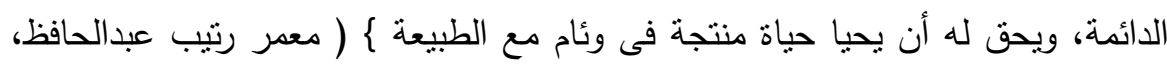

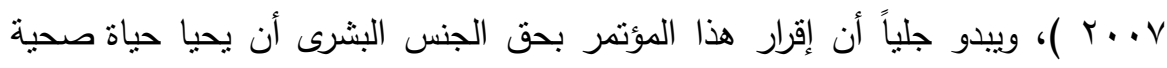

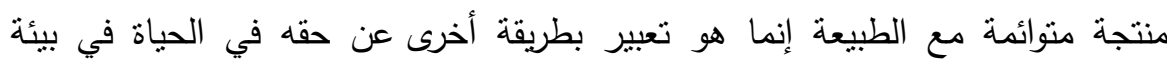

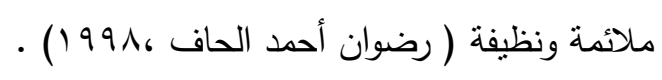

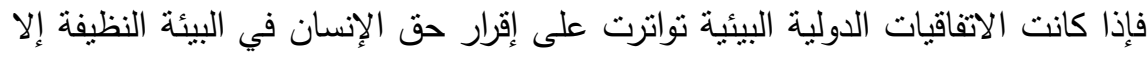

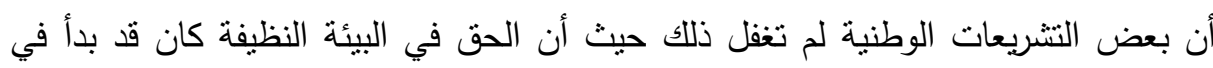

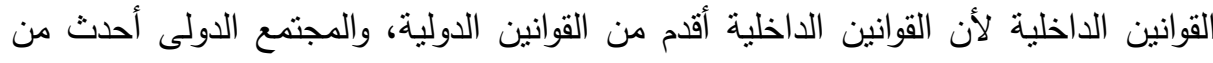

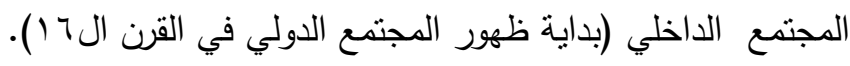

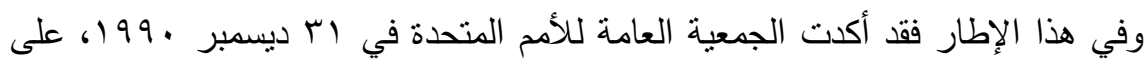

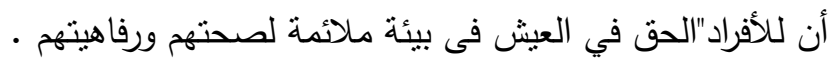

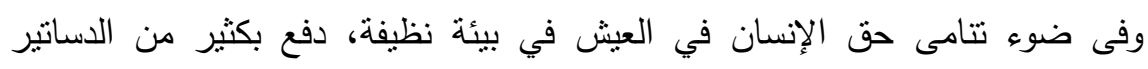
الحديثة إلى تخصيص مكانة هامة لهذا الحق ضمن أحكامها، وعلى رأسها الدستور الفرنسي

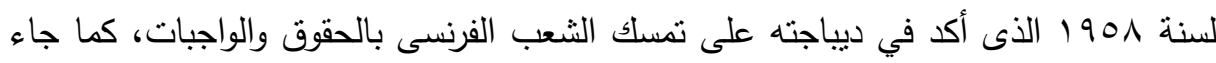

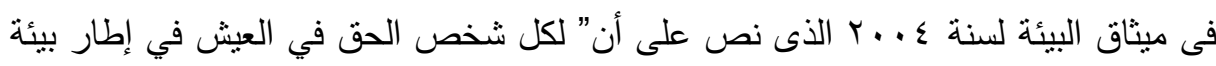


متوازنة وقادرة على ضمان صحته" وفي قانون حماية وتحسين البيئة الليبي رقم 10

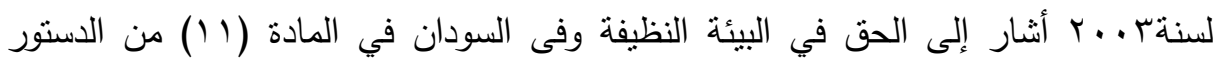

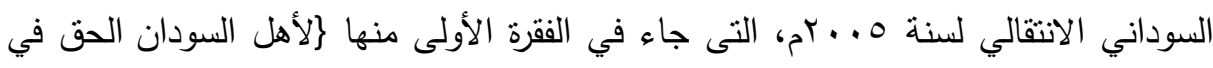

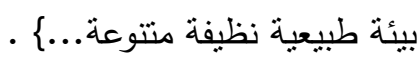
وتواترت دساتير الدول فى إقرار هذا الحق ومنها الدستور البرتغالى والأسبانى والتركى والكورى وغير ذللك.

وعقب موجة الحراك التي عرفتها كثير من الدول العربية مؤخرا والتي أعقبتها تعديلات

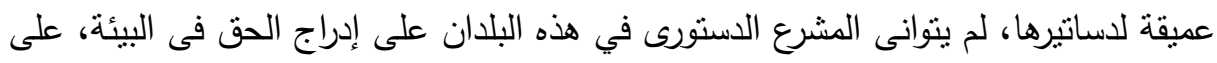

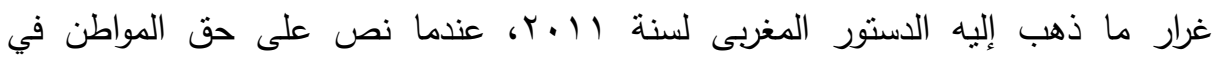
الحصول على الماء والعيش في بيئة سليمة؛ وتتمية مستدامة، وفى نفس الاتجاه الذي يسلكه

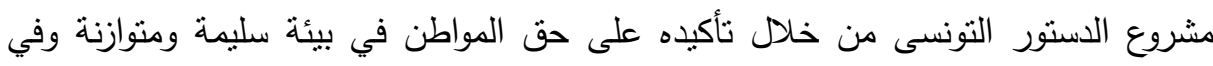

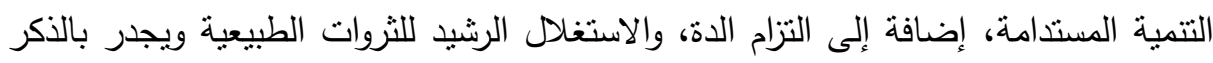

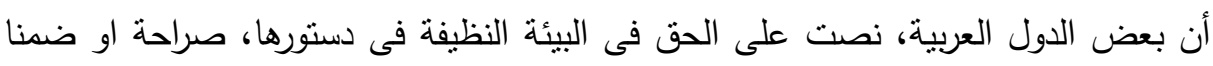

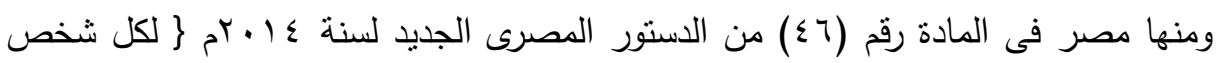
الحق فى بيئة صحية سليمة، تلنزم الدولة بصون البيئة وحمايتها من التلوث، واستخدام الموارد الطبيعية بما بكفل عدم الإضرار بالبيئة، والحفاظ على حقوق الأجيال فيهاج.

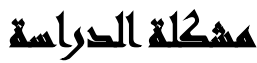

• من خلال مراجعة بعض قرارات الأمم المتحدة والاتفاقيات الدولية والوثائق المتعلقة بالبيئة متل (العهد الدولي الخاص بالحقوق الاقتصادية والاجتماعية والثقافية الصادر عن الأمم

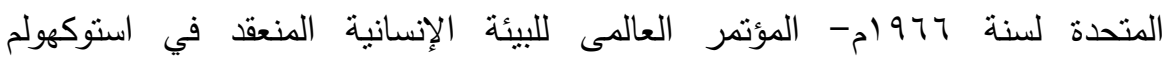

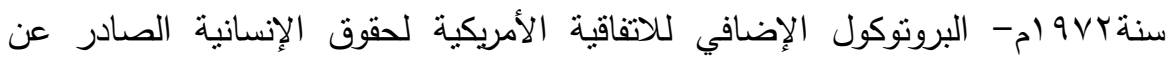

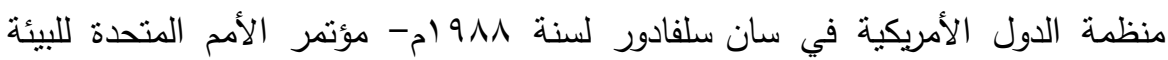

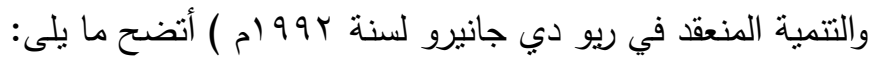


• عدم إدكانية توجه الأفراد رسمياً إلى أى هيئة دولية لتنظلم من أجل إهدار حقها فى البيئة

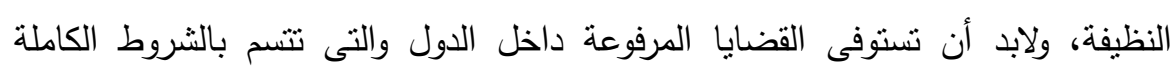
والمعقدة. • لا يوجد نص صريح يوضح حق الفرد في بيئة نظيفة فى الدستور المصرى القديم (واجب

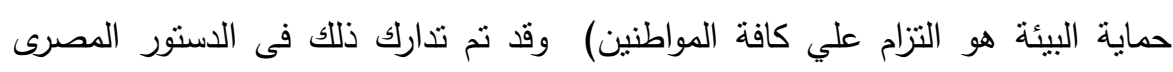

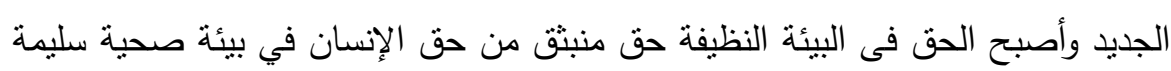
مساريا الدستور الفرنسى فى ذلك.

• غياب نوازن القوى بين الدولة الدنضررة والدول التى انتهكت حق الإنسان فى البيئة النظيفة

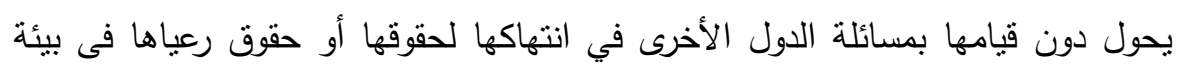

$$
\text { نظيفة. }
$$

• إن المؤتمرات الدولية أو المواثيق الدولية لا تصدر معاهدات ملزمة التطبيق وإنما نوصيات

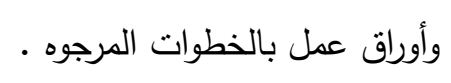

\section{تمساولاهت التواسمة}

وضع الباحث مجموعة من التساؤلات يوضح بها التغيرات المستقلة والتابعة والعلاقة

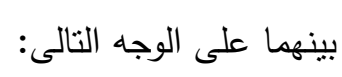

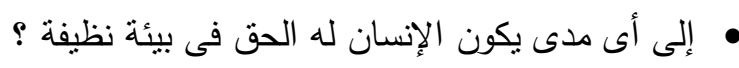

• إلى أى مدى وفقت الاتفاقيات الدولية في إدماج الحق في بئية بئة نظيفة كحق من حقوق الإنسان؟

• إلى أى مدى تكون المسئولية الدولية عند انتهاك الحق فى البيئة النظيفة الثابت للاول

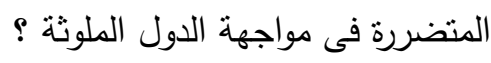

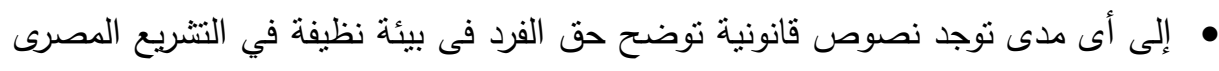

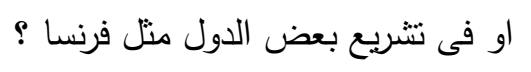
• إلى أى مدى يكون القانون الدولي لللييئة له القدرة على تحديد الدسئولية الدولية عن الدئ

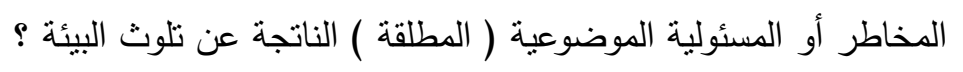




\section{أهساهي الترواسة}

موضوع الاراسة يهـف إلى:

• وضع إطار قانوني لحماية حق الانسان في العيش ببيئة سليمة ومتوازنة، لتوفير الحماية

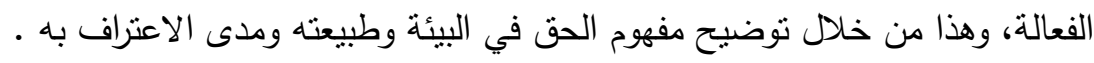

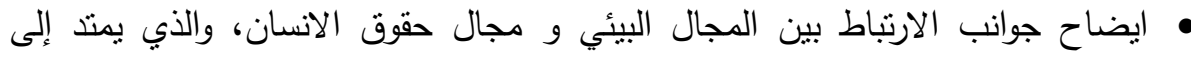
معالجة القضايا والمشاكل البيئية المتداخلة .

• رصد التوجهات الدولية والاقليمية و الوطنية المتخذة لمعالجة مختلف القضايا المتعلقة بحماية البيئة، ومدى حماية هذا الحق من طرف مختلف آليات حماية البيئة وحماية حقوق

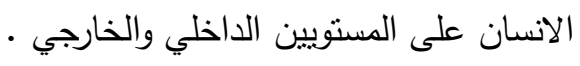

• وإنّ حقوق الإنسان البيئية لا يمكن أن تتم إلا من خلال تبنى أهداف التنمية المستدامة ممثلة بالمساواة بين الأجيال الحاضرة وأجيال المستقبل فى عملية مشاركة الإنه الجمهور ومؤسسات المجتمع المدني في صناعة القرار التتموى من خلال عملية تقييم الأثر البيئى وهو إحدى أهم الآليات في حقوق الإنسان البيئية ليمكن المجتمعات من حماية حقوقها البيئية .

إتاحة المعلومات البيئية حول حجم ومدى الضرر البيئى للمشاريع التتموية وتبنى مبدأ الملوث هو الدافع للحفاظ على حقوق الإنسان وطبيعة بيئته ومواردها الغير متجددة حيث ليث أن الدولة في القانون الدولى هى السلطة التنفيذية تبذل الجهد لتفى بالتزاماتها الثخصية

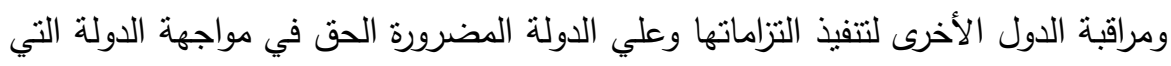

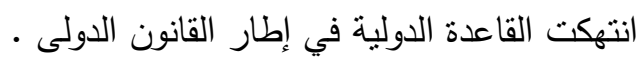




\section{أهمية السوراسة}

أولاً: بالنسبة للأفراد: هو محاولة إيجاد حماية للأفراد للتنتع بالحق في البيئة النظيفة والتوصل إلي طرق قانونية للمطالبة بهذا الحق.

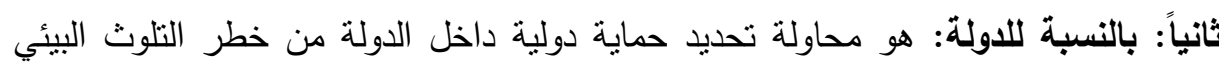

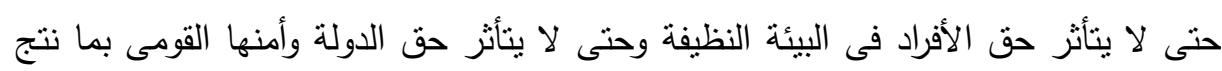

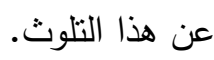

حيث أن أساس المسئولية الدولية في القانون الدولى للبيئة هي المسئولية الموضوعية

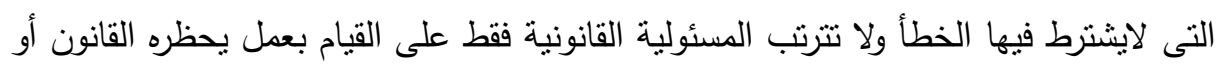

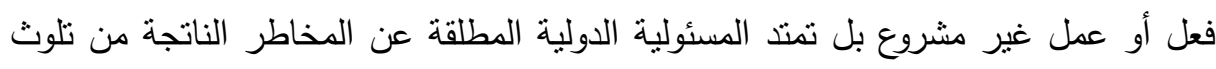
البيئة .

\section{منهمبي الصوراسة}

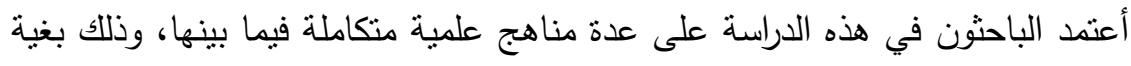

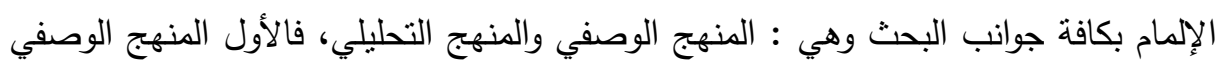

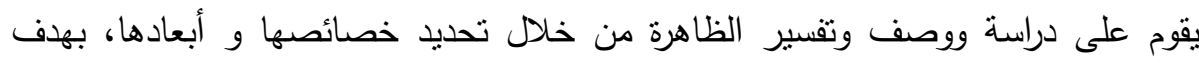

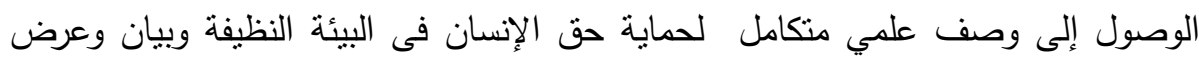

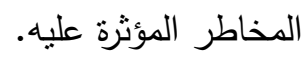

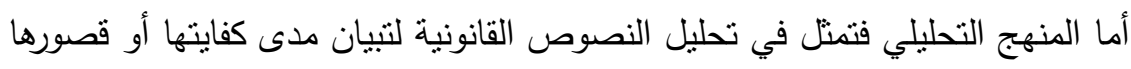

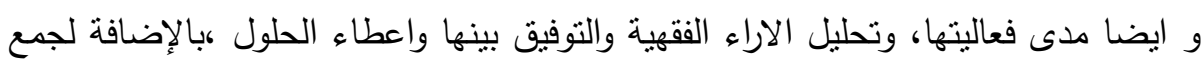

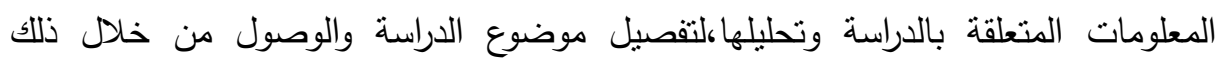

$$
\text { للأسلوب الأمثل لمواجهه المشكلة . }
$$

وقد استعان الباحثون بالعديد من المراجع العربية والأجنبية والرسائل العلمية والدوريات والنشرات والتقارير ومطبوعات المؤتمرات الدولية المختلفة بالإضافة إلى المواقع الإلكترونية الكاتية

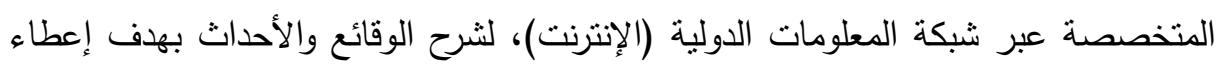
صورة واضحة عن ماهية الموضوع وجوانبه المختلفة . 


\section{التراسايت الصايرية}

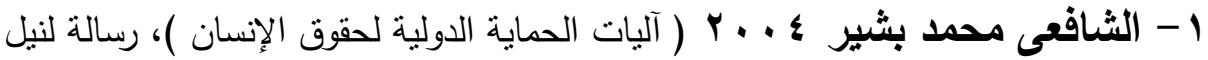
درجة الدكتوراة، كلية الحقوق جامعة المنصورة، تتاول فيها الحماية الدولية للاقليات واللاجين والاتجار فى البشر ثم تتاول الملامح العامة لحقوق الانسان فى الوقت الراهن من خلال تطور المركز القانونى للفرد فى الاتفاقيات الدولية لحقوق الاتسان، ثم تتاول تطور

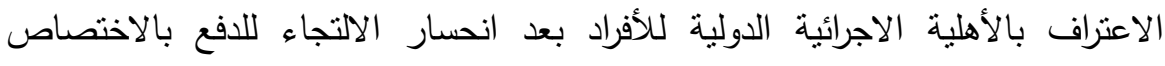

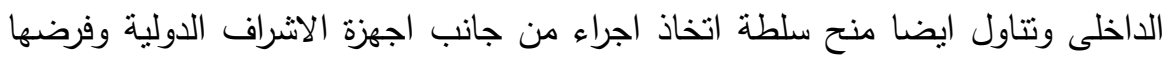
بصورة تدريجية، واليات تتفيذ حقوق الانسان المختلفة الاكثر فاعلية فى التطبيق على الثى

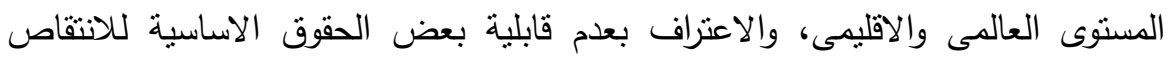

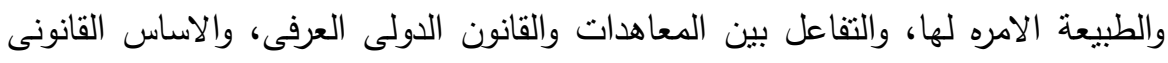
لحق الافراد فى الثكوى بالاتفاقيات الدولية لحقوق الانسان، وتتاول التقسيم الفقهى للحقوق والحريات العالمية وفقا للاتفاقات الدولية العامة والعهد الدولى للحقوق الددنية والسياسية، وتتاول اهم الحقوق محل الحماية ثم دور الوكالات المتخصصة فى مجال حقوق الانسان

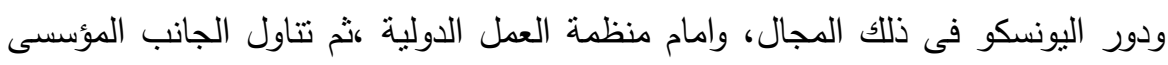
للآليات العالمية لحقوق الانسان فى اطلئ دور منظمة الامم المتحدة، ثم تتاول الآليات القضائية لحماية حقوق الانسان من خلال اختصاصات محكمة العدل الدولية والمحكمة الجنائية الدولية، وخلصت الدراسة الى بعض التوصيات للاول بالاشتراك فى المعاهدات الدولية لحماية حقوق الانسان.

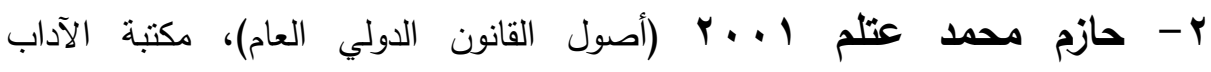

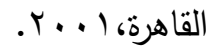

وتتاولت الدراسة بالتحليل مفهوم الثخصية القانونية الدولية مشيرا إلى تعدد أثخاص القانون الدولي العام ولم تعد الدولة أو الدول في ظل نظم القانون الدولي المعاصر الثخص الوحيد للقانون الدولي و لكن تعد الثخص الرئيسي حيث برزت داخل نظم القانون الدولي

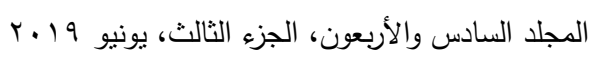


أنخاص مستحدثة لذلك القانون وتتاولت طبيعة نظام الاعتراف بأثخاص القانون الدولي من

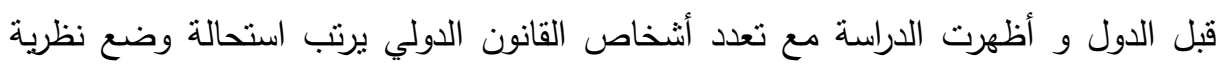

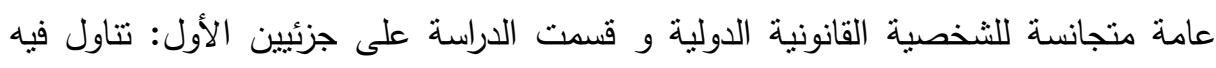

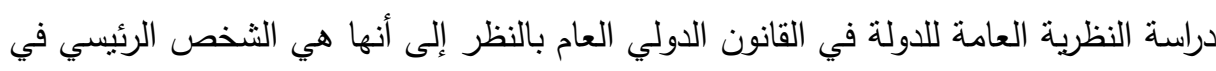

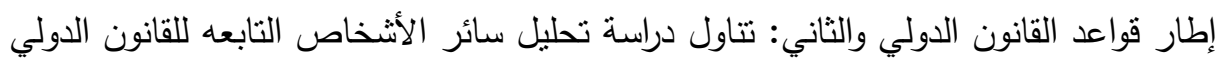

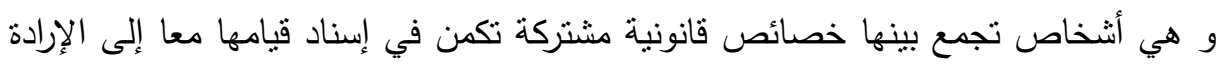
الثنارعة للاول ذاتها.

ץ- رضوان أحمد الحاف 1991 ( (حق الأنسان فى بيئة سليمة فى القانون الدولى العام)

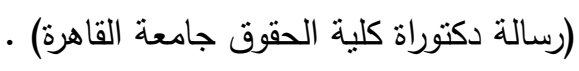

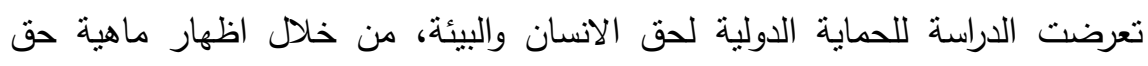

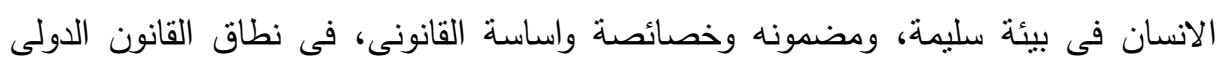

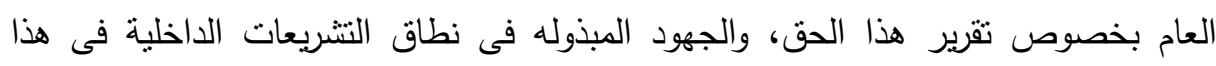

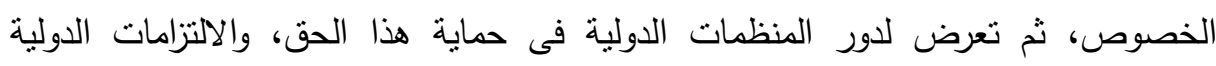

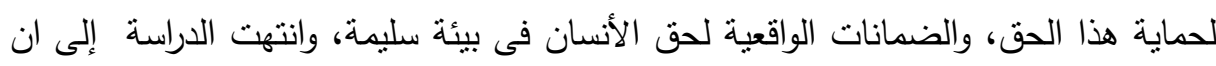

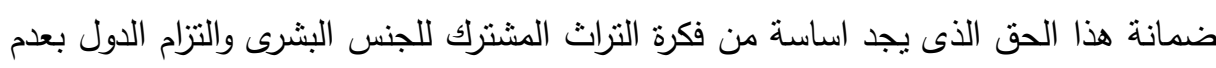

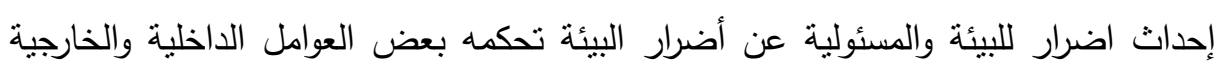

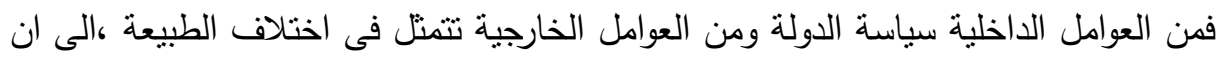

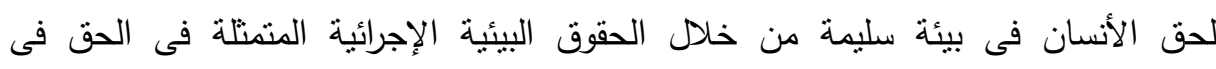

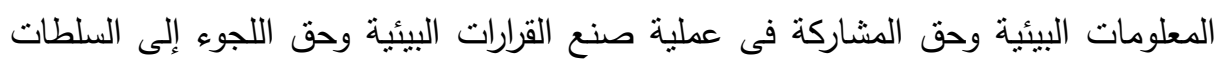

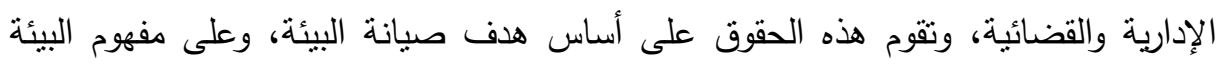

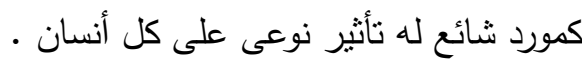

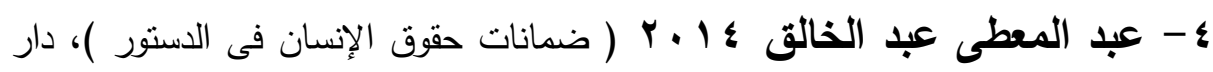

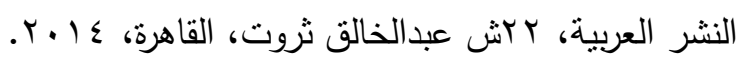

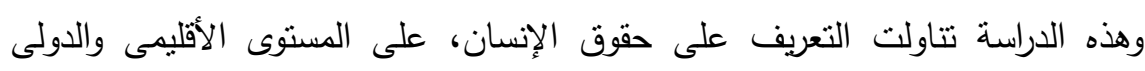

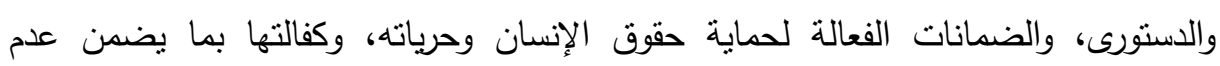
284

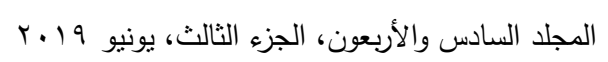


انتهاكها، وتوفير الحماية الحقيقة لهذه الحقوق والحريات التى تكفل للأفراد ممارستها والاستفاده

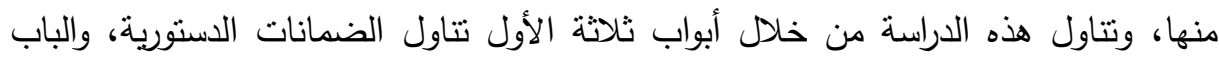

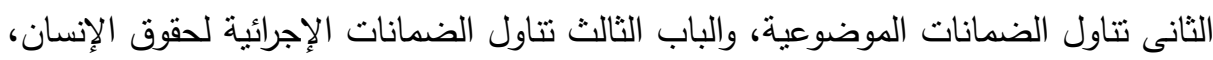

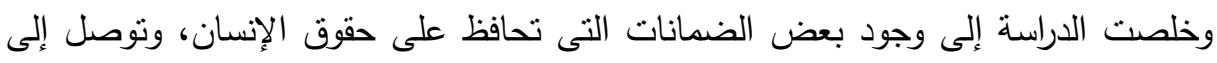
أن النص الدسنورى على حقوق الإنسان ليس بالأمر الكافى لضمان هذه الحقوق وكفالتها

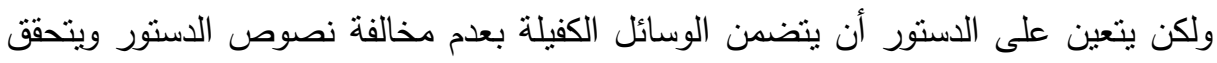

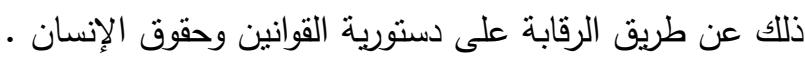

ه - محسن عبدالحميا أفكرين 999 ا (النظرية العامة للمسئولية الدولية عن النتائج الضارة عن افعال لايحظرها القانون الدولى مع إثارة خاصة لتطبيقها فى مجال البيئة )،

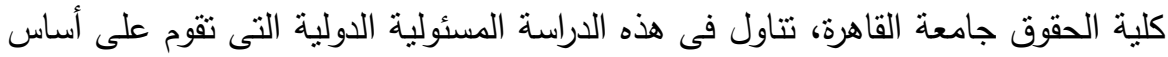

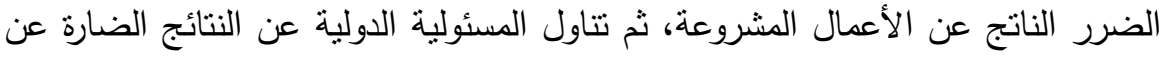
افعال لايحظرها القانون الدولى، والمسئولية الموضوعية، وتوصل إلى ان الضرر العابر للحدود الناتج عن ممارسة الانشطة داخل او خارج حدود الولاية الوطنية او الاقليمية للاولة المسئولة عن الضرر العابر للحدود ويخضع هذا الركن من أركان المسئولية

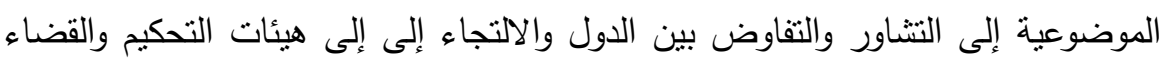

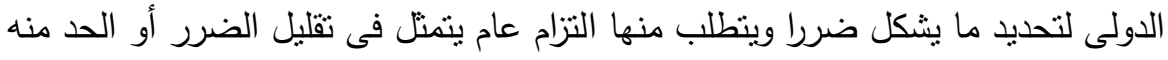

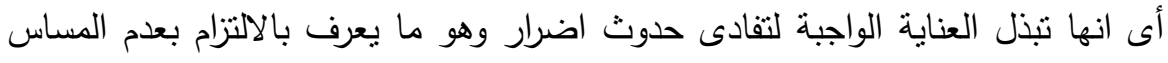

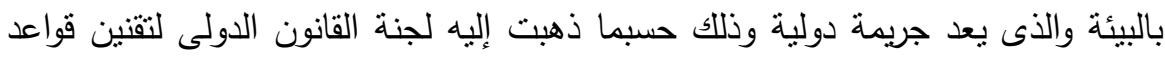
قانونية تتعلق بنظام المسئولية الدولية عن النتائج الضارة عن أفعال لايحظرها القانون

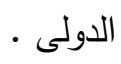

\section{الإطالر المنظرى}

تسعى هذه الدراسة إلى وضع إطار قانوني لحماية حق الانسان في العيش فى بيئة سليمة ومتوازنة، لتوفير الحماية الفعالة، وهذا من خلال نوضيح مفهوم الحق في البيئة النظيفة وطبيعته ومدى الاعتراف به، و ايضا جوانب الارتباط بين المجال البيئي و مجال

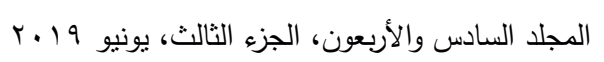




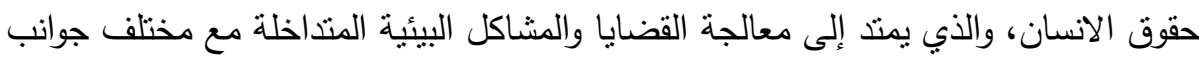
و أنواع حقوق الانسان، ومن هنا تم الكثف عن أبعاد وانعكاسات العلاقة بين قضيتين هامنين

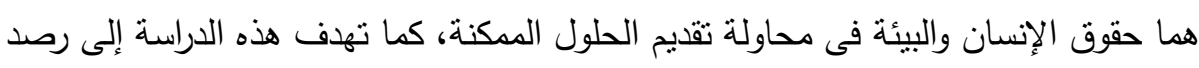
التوجهات الدولية و الاقليمية و الوطنية المتخذة لمعالجة مختلف القضايا المتعلقة بمسألة التصريح بهذا الحق وسبل الحماية، و هذا من خلال آليات حماية البيئة على المستويين

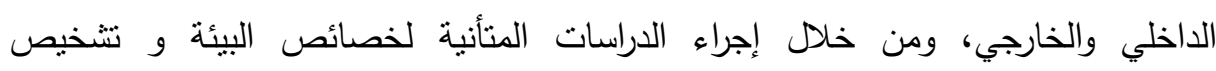

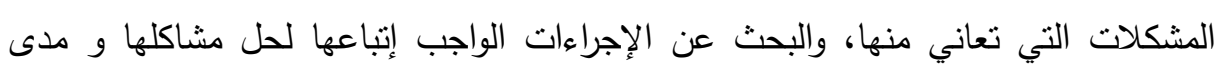

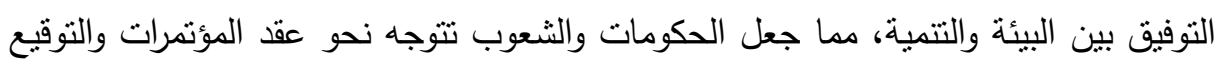

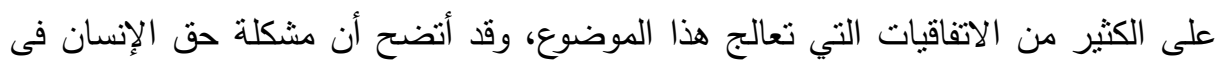

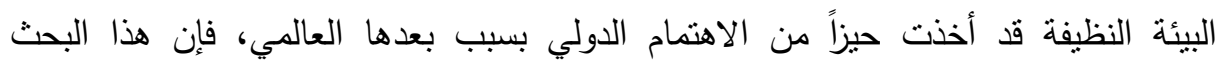

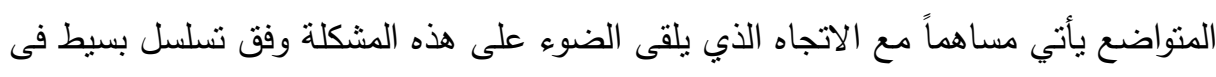

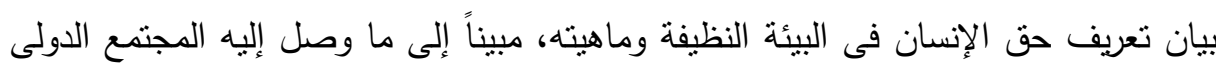

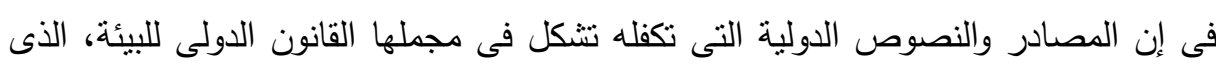

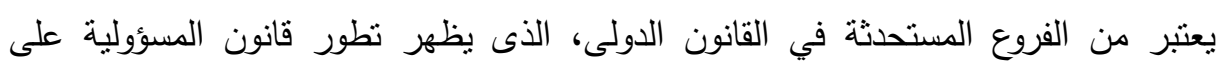

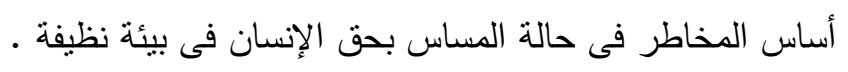

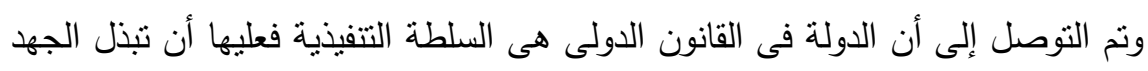

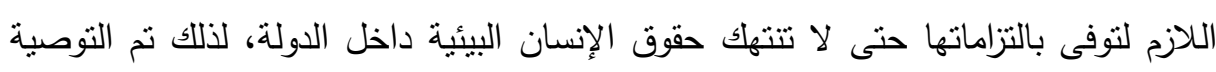

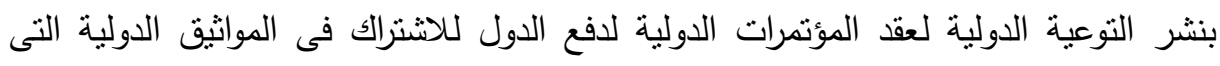

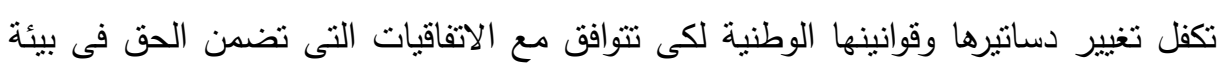

\section{إجبراءاهت التواسمة}

انطلاقا من الإثكالية الرئيسية للبحث والتساؤلات الفرعية المترتبة عنها ،والمناهج

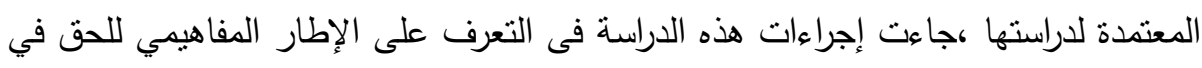
البيئة النظيفة والذي تم البحث وتقصي حقيقة هذا الحق من حيث مفهومه وطبيعته القانونية و ايضا أثخاصه المشمولين بالحماية، فى ضوء العهد الدولى لحقوق الإنسان وكذا المؤتمرات 
الدولية بداية من مؤتمر استوكهلم وتم التوصل إلى مختلف تداخلات قضايا البيئة بحقوق الانسان والتي تبرز من خلال المخاطر البيئية الرئيسية التي تهدد حقوق الإنسان لتمتذ إلى لى

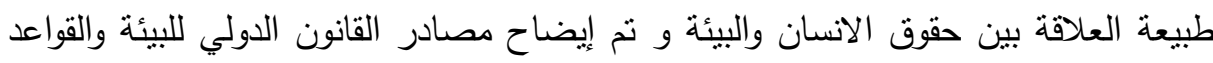

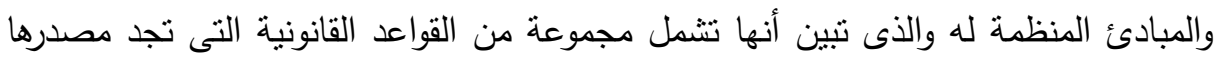

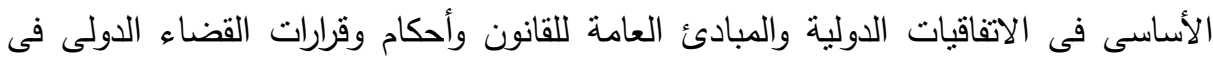

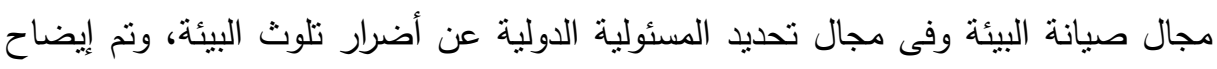

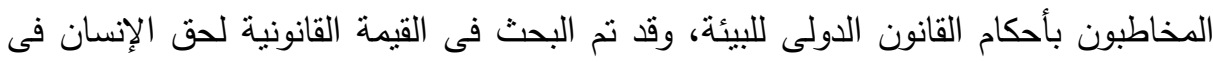

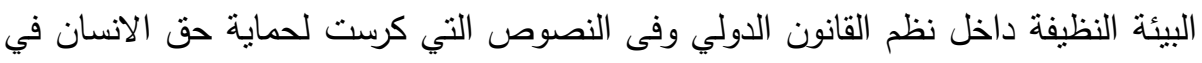
العيش ببيئة سليمة، تتجلى هذه القيمة من خلال بيان أسسه القانونية المختلفة الدولية

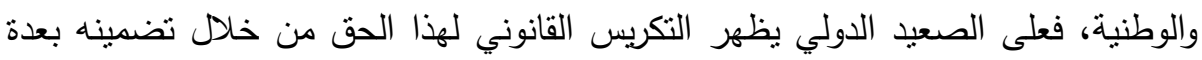

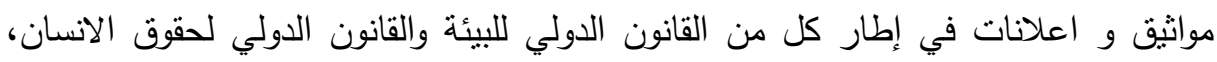

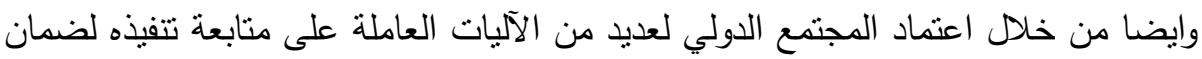

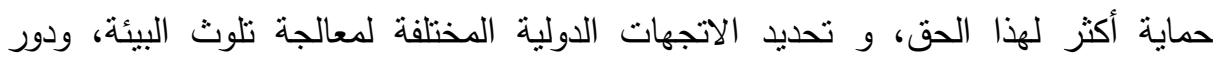
المنظمات الدولية فى مجال حماية البيئة من التلوث، وقد أنضح ذللك فى تفسير طبيعة دور

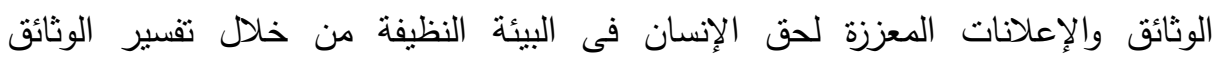
والإعلانات العالمية والوثائق والإعلانات الإقليمية، وأظهار حق الإنسان الإنسان فى البيئة النظيفة المشتق من القاعدة العرفية للقانون الدولي العام، ومن خلال عرض المعارسات الدبلوماسية للاول و القضاء الدولى والتتريعات الداخلية للدول، وتم تتاول طبيعة المسئولية القانونية عند انتهاك حق الإنسان فى البيئة النظيفة وأنضح ذلك من خلاد تحديد ماهية المسئولية الدولية

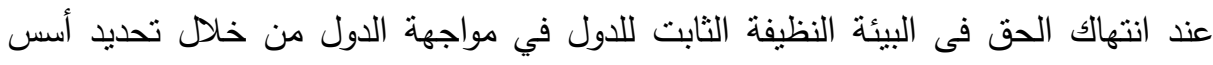

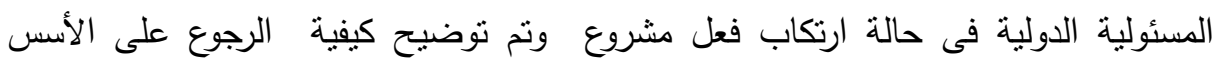

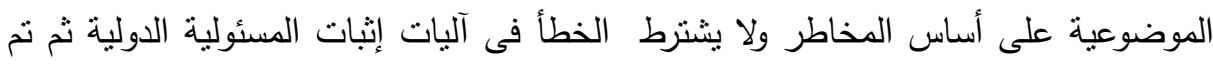
توضيح نظم المسئولية عند انتهاك حق الإنسان فى البيئة النظيفة من خلاسل كيفية تحديد 
مسئولية الدولة والأفراد فى التشريع الفرنسى والمصرى عن طريق إثبات الحق عن طريق الحق فى الصحة.

\section{المنيأئم}

خلص البحث إلى مجموعة من النتائج أكلت على ماجاء بها من تساؤلات كالتالى:

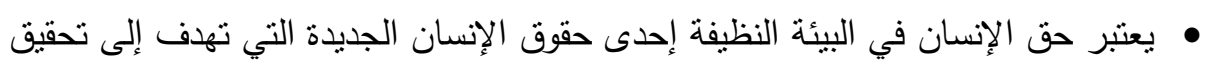
احترام كرامة الجنس البشرى فى الحياة، لتعرضه للإعتداء وصعوبة الوقاية من مخاطره.

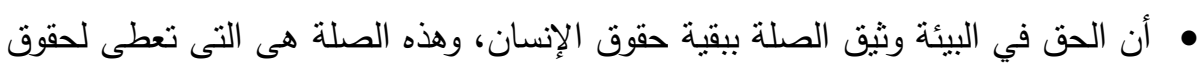

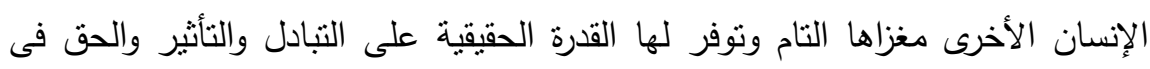
إعادة الحال إلى ما كان عليه، والحق في التعويض.

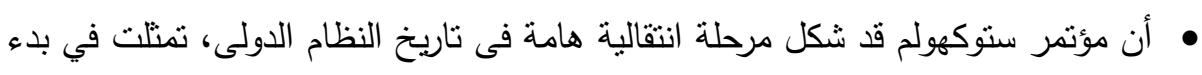

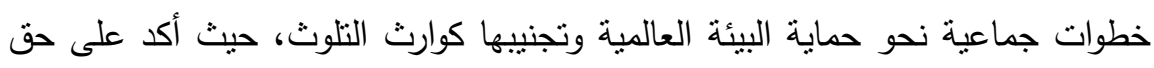
الإنسان فى الحياة ببيئة نظيفة ومستدامة، كما أكد على مبدأ مسئولية الدولة عن الأضرار

• إن المصادر والنصوص الدولية التى تكفل حماية البيئة تشكل فى مجلها القانون الدولى للبيئة، الذى يعتبر من الفروع المستحدثة في القانون الدولى، كما نظهر أهمية هذا الفرع لئه

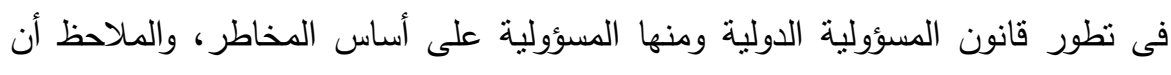
هذا الفرع يحتاج إلى صياغة قواعد دولية جديدة لمواجهة المخاطر البيئية الجديدة لا سيما

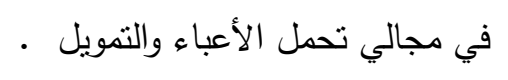
• تحقيق التتمية على حساب الاعتبارا ت البيئية، يهدد البشرية وكوكب الأرض والأجيال القادمة. • أن حق الإنسان في الحياة في بيئة نظيفة، أصبح من الحقوق الأساسية التي تضمنتها

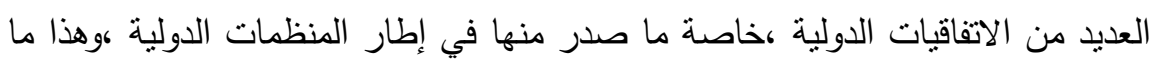
جعله حقاً دولياً يحميه القانون الدولي. 
• أن صدور الدستور المصرى عام ؟ اـبام جاء معاصراً لانتشار الديمقراطية الاجتماعية

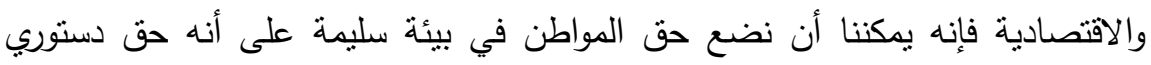
باعتباره أحد هذه الحقوق الاجتماعية. •تعد مصر من الدول التي عملت على اتباع توصيات المؤتمرات الدولية، وإصدارها تشريعات خاصة تحافظ بها على البيئة .

\section{اللمهوصيايق}

• ضرورة تعزيز التكامل بين النظم القانونية الدولية العالمية والاقليمية لتحقيق حماية أوفر

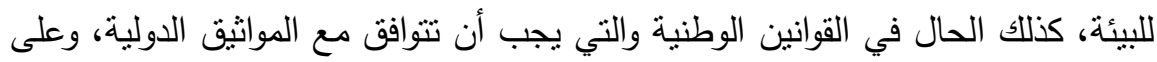
المشرع ضرورة تحقيق التتاسق والتكامل بين النصوص المتعلقة بحماية البيئة. • إلزام الدول الصناعية باستخدام التكنولوجيا النظيفة في الصناعة، حتى يصل حجن حمث النفايات الخطرة المتولدة إلى الحد الأدن، مع الحرص على التخلص من تلك النفايات في بلد المنشأ

• ضرورة إنشاء صندوق لحماية البيئة يهذف إلى توفير الاستثمار للقطاع البيئى، وتقديم

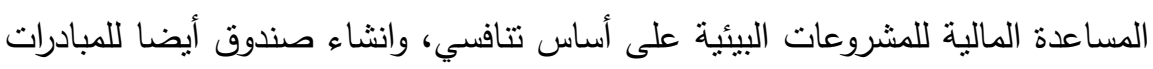
البيئية، يهدف إلى تشجيع مشاركة القطاع الخاص والجمعيات في مصر على الإدارة والممارسات البيئية السليمة، والأخذ بمبدأ الملوث هو الدافع كأهم أداة لمعاقبة ملوثي البيئة

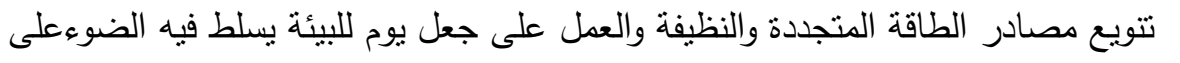
التغييرات البيئية ومسبباتها التى طرأت فى العام المنصرم وكيفية مجابهتها في العام الذى ولى ضرورة توحيد القوانين البيئية والتي لها علاقة بمختلف عناصر البيئة، وجعلها في مدونة قانونية واحدة ليسهل الإطلاع عليها حتى لا يعتذر شخص بالغلط في القوانين، وحتى

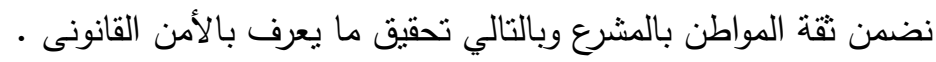




\section{المرانs}

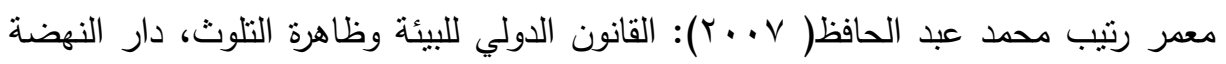

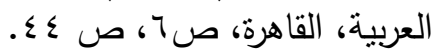

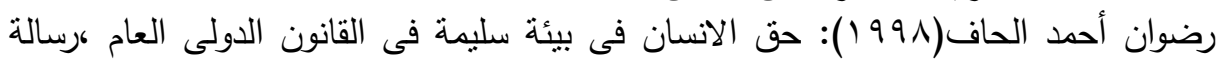

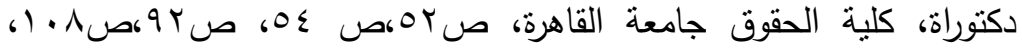

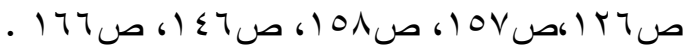

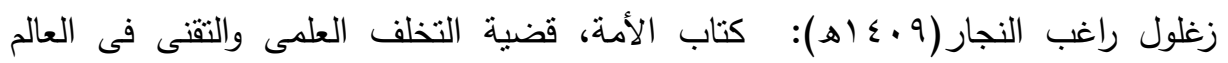

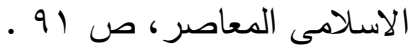

أحمد عبد الكريم سلامة(997 (19): قانون حماية البيئة الاسلامى مقارنا بالقوانين الوضعية، دار

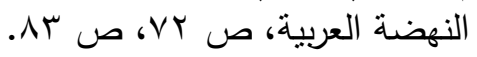

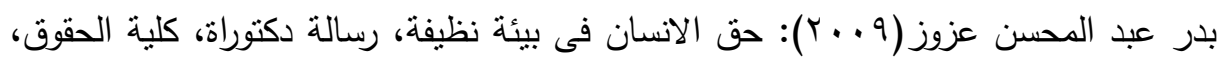

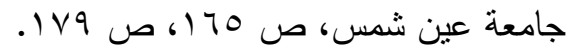

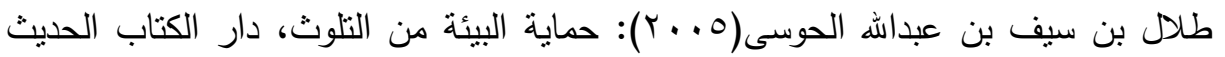

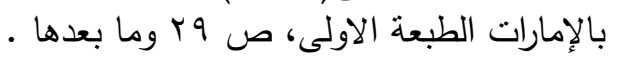

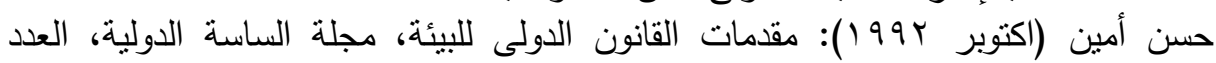

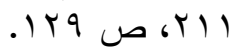

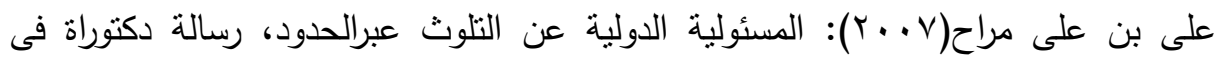

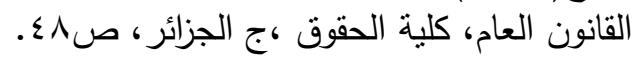

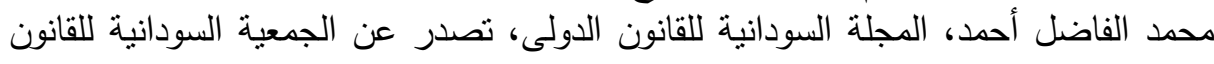

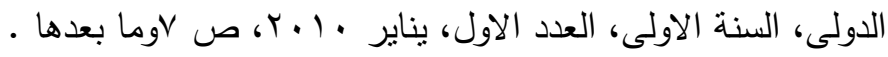




\title{
THE HUMAN RIGHT TO A CLEAN ENVIRONMENT BETWEEN THE SYSTEMS OF INTERNATIONAL LAW AND DOMESTIC LAW COMPARATIVE STUDY
}

\author{
Ahmed A. Abd Elkhalik. ${ }^{(1)}$;Elsayed E. Nayel. ${ }^{(2)}$ \\ and Hazem Atlam. (2)
}

1) Post Grad. Institute of Environmental Studies \& Research, Ain Shams University 2) Faculty of Law, Ain, Shams University

\begin{abstract}
The right to a clean environment is one of the most important rights in the field of public rights and freedoms. It belongs to the third generation of human rights. It is based on the idea of solidarity among the peoples of the world. It is not possible to eliminate the various damage to the environment that does not limit international borders, Only through the concerted efforts of international efforts to preserve the environment.

The difficulty of proving the damage caused by pollution of the environment, especially across the international border (whether as a result of legitimate or illegal work), lies in the mechanism of establishing the causal link between pollution and damage because the effects of pollution do not directly affect the individual or the State, Therefore, it is necessary to resort to what is known as international responsibility for risk, objectivity or absolute.

As the state in international law is the executive authority, it must make the necessary effort to fulfill its obligations so as not to violate the environmental human rights within the state. Therefore, it is necessary to spread the international awareness and hold international conferences to push countries to participate in international conventions that
\end{abstract}

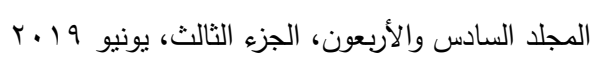


guarantee changing their constitutions and national laws Which guarantees the right to a clean environment through the right to health.

It was concluded that the human right to a clean environment has become one of the fundamental rights enshrined in many international conventions, especially those of international organizations, which has made it an international right protected by international law.

Therefore, it was recommended that environmental laws should be unified with regard to the various elements of the environment, and that they should be placed in a single legal code for easy access to them and subjecting environmental disputes to a specialized jurisdiction 